\title{
Ni/Photoredox Dual Catalysis Sulfone Compounds Synthesised with Carbon Nitride as the Semiheterogeneous Photocatalyst
}

\author{
Yang Liu†*, Joost Berkhong† \\ $\dagger$ Frontier Institute of Science and Technology (FIST), Xi'an Jiaotong University, Yanxiang Road 99, Xi'an, Shaanxi, 710054, \\ P. R. China.
}

Supporting Information

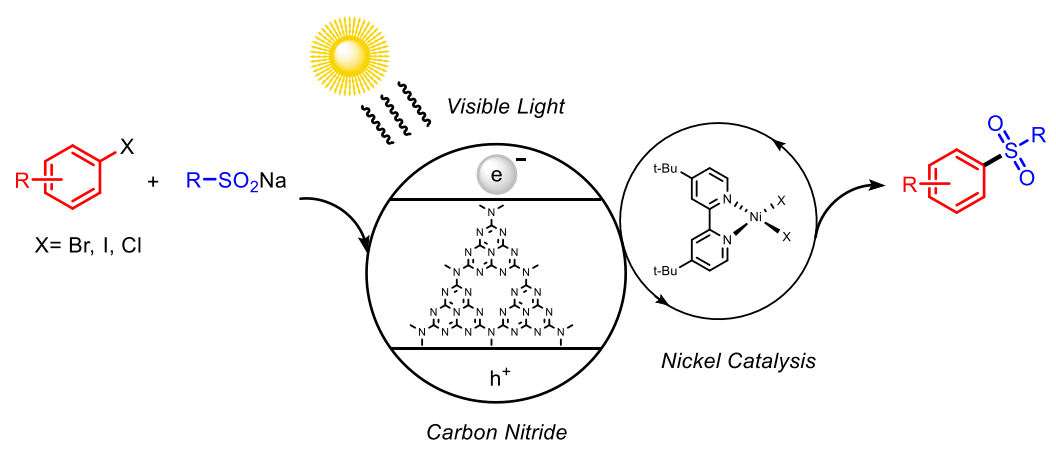

\begin{abstract}
An easily available heterogeneous semiconductor material, g-CN, proved to be feasible when combined with homogeneous nickel catalysts for light-mediated $\mathrm{C}\left(\mathrm{sp}^{2}\right)-\mathrm{SO}_{2} \mathrm{Ar}$ bond formation of aryl bromides with aryl sulfinates under mild conditions and base-free, unlocking a variety of cross-couplings. The metal-free heterogeneous semiconductor is totally recyclable from reaction system, and experimental results demonstrated a series of differently substituted substrates including electron donating groups and electron withdrawing groups can be tolerated with a satisfactory result. The method could even produce the classic drug Dapsone in large scale, showing strong practical application potential.
\end{abstract}

Visible light dirven photoredox catalyted has gained numerous attentions as a powerful and energy-efficient method for chemical synthesis. ${ }^{1}$ The central of concept is rely on oxidation addition with specific radicals from precursors and trapped by transition metal complex such as nickel, ${ }^{2}$ palladium, ${ }^{3}$ cooper ${ }^{4}$ and so on. ${ }^{5}$ After elimination by reduction, the desired crosscoupling product is generated and the metal complex is reducted through photocatalytic cycle for next process. However, the whole process is highly depended on homogeneous photoresponse catalysts, such as ruthenium, ${ }^{6}$ iridium $^{7}$ or organic dyes ${ }^{8}$ in numerous reports. It is a pity that these homogeneous photocatalysts are also accompanied by weakness such as the expensive expenses, separation from products, unable to recycle which limites the actual industrialized application to a certain extent.

Based on the actual background and requirement, in recent years, some repersentive heterogeneous catalyst such as g- $\mathrm{CN},{ }^{9}$ $\mathrm{TiO}_{2},{ }^{10} \mathrm{CdS}^{11}$ involved in photoredox process has been gradually developed. König' groups ${ }^{9 a}$ reported ligand-free mpg$\mathrm{CN} / \mathrm{Ni}$ dual photoredox catalytic protocols for $\mathrm{C}-\mathrm{N}$ bond formation, and explored mpg-CN/Ni-dual catalysis for $\mathrm{C}\left(\mathrm{sp}^{2}\right)$ $\mathrm{C}\left(\mathrm{sp}^{3}\right)$ cross-coupling reactions yielding diarylmethanes analogously. ${ }^{9 \mathrm{~b}}$ Pieber and Seeberger reported mpg-CN in combination with nickel catalysis can induce selective C-O cross-couplings of carboxylic acids with aryl halides. ${ }^{9 \mathrm{c}}$ Meanwhile, they also reported g-CN/Ni with light-mediated cross-couplings of aryl bromides with alcohols via $\mathrm{C}-\mathrm{O}$ bond formation. ${ }^{9 \mathrm{~d}}$

Inspired by previous investigation, ${ }^{12}$ we hence developed mpg-CN/Ni dual catalysis sulfone compounds synthesised which are widely found in a number of drug-active molecules such as Dapsone, Vismodegib and Intepirdine (Scheme 1a) via $\mathrm{C}\left(\mathrm{sp}^{2}\right)-\mathrm{SO}_{2} \mathrm{Ar}$ bond formation. Compared with the traditional method (Scheme 1b), ${ }^{13}$ this kind of heterogeneous photocatalyst invovled in photoredox have the potential for industrial and large-scale development due to its advantages including mild conditions, visible light driven, base-free, high-yield outcomes and reutilization.

In our consideration of this approach and previous report, ${ }^{14}$ we envisioned that aryl sulnate salts have low redox potentials $\left(\mathrm{E}_{1 / 2}=-0.37 \mathrm{~V} \text { vs. } S C E \text { in } \mathrm{CH}_{3} \mathrm{CN}\right)^{15}$ and could undergo single electron transfer oxidation by photogenerated hole form excited $\mathrm{g}-\mathrm{CN}$ which is effective to generate sulfonyl radicals. Oxidative addition of $\mathrm{Ni}(0)$ species to an aryl halide delivers the $\mathrm{Ni}(\mathrm{II})$ intermediate $^{14}$ which is tend to trap the sulfonyl radicals yielding a $\mathrm{Ni}$ (III) organometallic adduct. Subsequent reductive elimination produces the targeted $\mathrm{C}\left(\mathrm{sp}^{2}\right)-\mathrm{SO}_{2} \mathrm{Ar}$ cross-coupling product. Finally, the electron form semiconductor surface is utilized for the reduction of the $\mathrm{Ni}(\mathrm{I})$ species to $\mathrm{Ni}(0)$ species through another single electron transfer to complete the whole Ni catalytic cycle (Scheme 1c).

Scheme 1. Significant of Sulfones and Experimental Design 


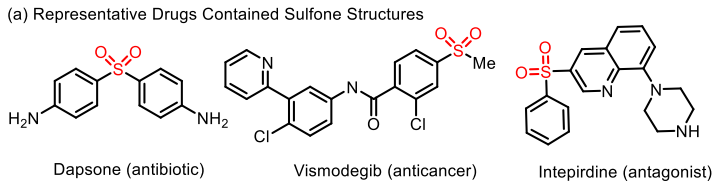

(b) Traditional Methods to Obtain Sulfone Compounds

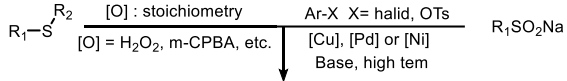

$$
\begin{aligned}
& \mathrm{R}_{1} \text { "s" }^{\mathrm{O}} \mathrm{R}_{2}
\end{aligned}
$$

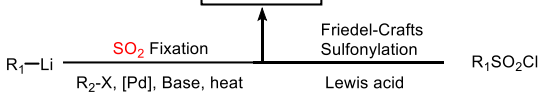

(c) Reaction Design about Ni/photoredox Catalysis $\mathrm{C}_{\mathrm{sp}}{ }^{2}-\mathrm{SO}_{2} \mathrm{Ar}$ Bond Formation Using Carbon Nitrides

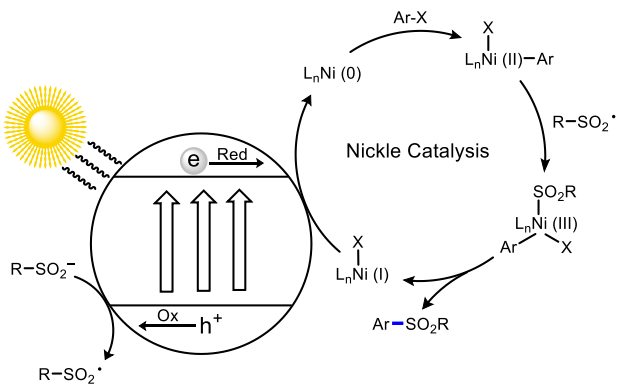

With this design in mind, we began to inveatigated the possibility and figure out the best conditions primarily. According to the Table 1, 4-bromotoluene 1a and sodium benzenesulphinate $\mathbf{2 a}$ was choosed to be the model substrate reseparately. To our delight, the product 1-methyl-4-(phenylsulfonyl) benzene 3a was obtained with the excellent yield up to $82 \%$ under $45 \mathrm{~W}$ blue led $(455 \mathrm{~nm})$ irradiation and $10 \mathrm{wt} \%$ of $\mathrm{g}-\mathrm{CN}$, (Synthesis method was shown in Support information, SI), $5 \mathrm{~mol} \% \mathrm{NiBr}_{2}$ -DME and 10 mol\% $\mathbf{L 1}$ added in DMF as the standard conditon (entry 1). Then, the reaction could not be happened when the absence of light, g-CN, or nickel catalyst respectively (entry 2). We chooesd the $\mathrm{Ni}(\mathrm{COD})_{2}$ as the nickel source but a modest yield was acquired (entry 3). Meanwhile, we also investigated the ligand effect to this reaciton system. Firsty, when no ligand was involved, the producted 3a did not observed at all (entry 4), and we changed similar ligands such as $\mathbf{L 2}$ or $\mathbf{L 3}$, but an unsatisfactory result (entry 5, 6) was shown. $\mathrm{MeCN}, \mathrm{MeOH}$ or acrtone was selected to be solvent respectively, but trace producted was detected (entry 7). Shortening reaction time to $12 \mathrm{~h}$, the yiled was decreased to $68 \%$ accordingly (entry 8 ). The reaciton colud not be occurred without degasing (entry 9). Under the same conditions, chlorobenzene was introduced but unsatisfactory results were obtained, and we also chooed the iodobenzene as the substrate could also obtain 3a up to $78 \%$ yield (entry 10).

Table 1. Screening Data for the Optimization of the Reaction Conditions towards phosphine oxide 3a. ${ }^{a}$

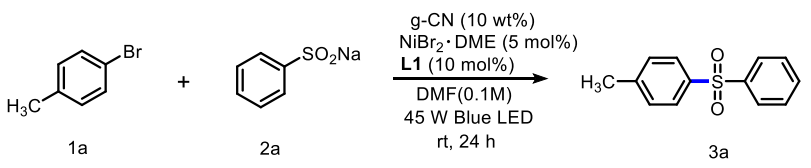

\begin{tabular}{lll} 
Entry & Deviation from initial conditions & Yield of $3 \mathrm{a}^{\mathrm{b}}(\%)$ \\
\hline
\end{tabular}

\begin{tabular}{|c|c|c|}
\hline 1 & none & 82 \\
\hline 2 & no light, no mpg-CN, no nickel catalyst & N.D. \\
\hline 3 & $\mathrm{Ni}(\mathrm{COD})_{2}$ instead of $\mathrm{NiBr}_{2} \cdot \mathrm{DME}$ & 37 \\
\hline 4 & no ligand & N.D. \\
\hline 5 & $\mathrm{~L} 2$ instead of $\mathrm{L} 1$ & 21 \\
\hline 6 & L3 instead of L1 & $<5$ \\
\hline 7 & $\mathrm{MeCN}, \mathrm{MeOH}$ or acetone instead of DMF & trace \\
\hline 8 & $12 \mathrm{~h}$ instead of $24 \mathrm{~h}$ & 68 \\
\hline 9 & no degas & N.D. \\
\hline 10 & chlorobenzene or iodobenzene as the substrate & 32,78 \\
\hline
\end{tabular}

${ }^{a}$ Reaction conditions: 1a $(0.10 \mathrm{mmol}, 1.0 \mathrm{eq}), \mathbf{2 a}(0.15 \mathrm{mmol}, 1.5 \mathrm{eq})$, g$\mathrm{CN}$ (10 wt \%), $\mathrm{NiBr}_{2} \bullet \operatorname{DME}(5 \mathrm{~mol} \%), \mathrm{L} 1$ (10 mol\%), DMF (1 mL, $\left.0.1 \mathrm{M}\right)$, 45W blue LED, rt, $24 \mathrm{~h}, \mathrm{~N}_{2}$. ${ }^{\mathrm{b}}$ Determined by crude ${ }^{1} \mathrm{H}-\mathrm{NMR}$ with toluene as the internal standard. N.D. = not detected. DMF $=\mathrm{N}, \mathrm{N}^{\prime}$-dimethylformamide.

We then used the optimized reaction conditions to explore the scope of the reaction with respect to the variation of different substituted bromobenzene. As shown in Scheme 2. various aryl bromides substituted with electron donating group including methyl 3a, 3i, 3o, methoxy group 3n, tert-butyl 3f, or phenyl $\mathbf{3 h}$, Naphthalene $3 \mathbf{r}$ or strong electron withdrawing group including trifluoromethyl $\mathbf{3 c}, \mathbf{3 j}, \mathbf{3 p}$, fluorine atom $\mathbf{3 d}, \mathbf{3 k}, \mathbf{3 q}$, cyan $\mathbf{3 e}, \mathbf{3 l}$ at different positions $(\mathrm{o}, \mathrm{m}, \mathrm{p})$ were reacted very well, generating the corresponding products with moderate to high yields. In addition, 1-methyl-5-(phenylsulfonyl)-1H-indole $3 \mathrm{~s}$ also could be obtained and some heterocyclic compounds like pyridine $3 \mathbf{t}$, thiazole $\mathbf{3 u}$ and furan $\mathbf{3 v}$ were also tolerated successfully via this method with bromide alternatives as the reagent.

\section{Scheme 2. Substrate Scope of Aryl Halide ${ }^{a}$}
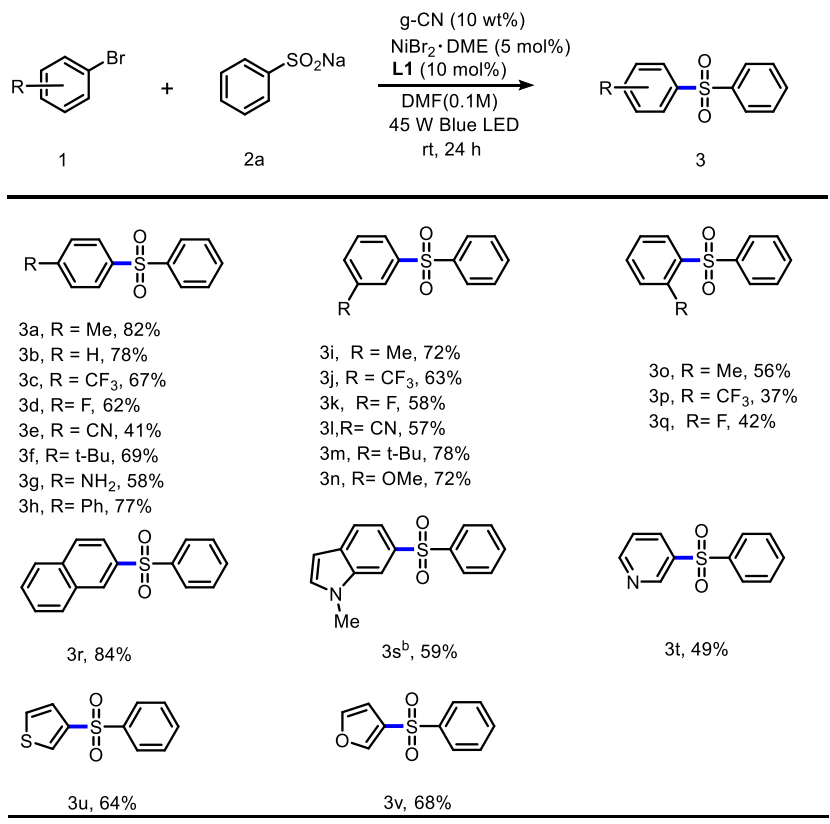
${ }^{a}$ Reactions were performed under the standard conditions (Table 1, Entry 1) and isolated yields were reported. ${ }^{\mathrm{b}}$ Aryl iodide and 3.0 eq of sulfinate salt were used as the substrate.

In order to further investigate the comprehensive scope of the reaction method, various sodium benzenesulfonates were selected to participate in modle reaction condion, and the corresponding good results were obtained similarly. As shown in Scheme 3, some of the common substituent groups like methyl $\mathbf{4 a}, \mathbf{4 f}, \mathbf{4 i}$, methoxy group $\mathbf{4 d}$, tert-butyl $\mathbf{4 e}$, Naphthalene $4 \mathbf{k}$ or trifluoromethyl $\mathbf{4 b}$, fluorine atom $\mathbf{4 c}, \mathbf{4 g}, \mathbf{4 h}$, chlorine $\mathbf{4 j}$ were proved to be compatible with suitable yield. In addition, pyridine compound $\mathbf{4 l}$ was suitable for this condition.

\section{Scheme 3. Substrate Scope of Sulfinate salt ${ }^{\mathrm{a}}$}

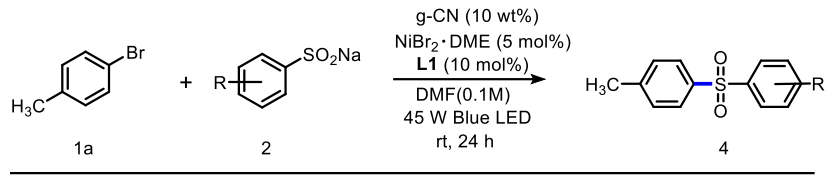

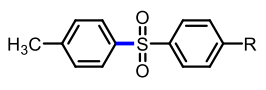
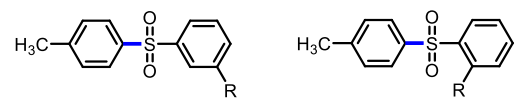

4a, $\mathrm{R}=\mathrm{Me}, 61 \%$
4b, $\mathrm{R}=\mathrm{CF}_{3}, 64 \%$

$4 \mathrm{c}, \mathrm{R}=\mathrm{F}, 68 \%$

$4 d, \mathrm{R}=\mathrm{OMe}, 62 \%$

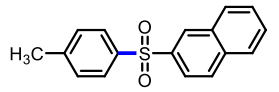

$4 \mathrm{e}, \mathrm{R}=\mathrm{t}-\mathrm{Bu}, 73 \%$ $4 \mathrm{f}, \mathrm{R}=\mathrm{Me}, 56 \%$
$4 \mathrm{~g}, \mathrm{R}=\mathrm{F}, 65 \%$

$4 h, R=F, 58 \%$ $4 \mathrm{i}, \mathrm{R}=\mathrm{Me}, 61 \%$ $4 \mathrm{j}, \mathrm{R}=\mathrm{Cl}, 60 \%$

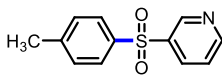

$4 \mathrm{I}, 59 \%$

${ }^{a}$ Reactions were performed under the standard conditions (Table 1, Entry 1) and isolated yields were reported. ${ }^{\mathrm{b}}$ Aryl iodide was used for the reaction partner.

Figure 3. Actual catalytic performance testing used in industrial manufacture

(a) Synthesis of drups dapsone on a gram scale

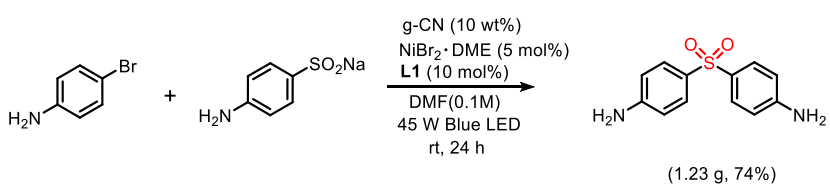

(b) Crude ${ }^{1} \mathrm{H}-\mathrm{NMR}$ yield of $3 \mathrm{a}$ in five consecutive runs with recovered g-CN (TEM attached)
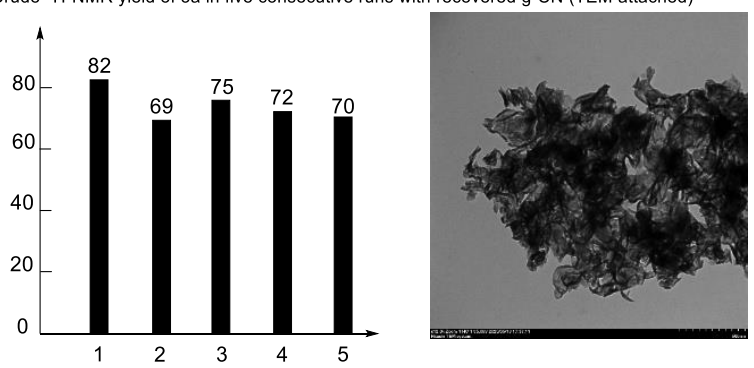

In view of dapsone is a famous bio-active molecule with the corresponding structure, we used the corresponding raw materials, through the standard explored conditions, to achieve the synthesis of this drug in large scale up to $74 \%$ yield successfully (Figure 1a). What's more, considering that the numbers of cycles from stabilization were the key to measure the practical application towards heterogeneous catalysts, we have studied the effect of g-CN though repeated to use. As shown in the Figure 1b, after each single reaction cycle, excellent conversion rate was obtained in spit of 5 times under the same conditions and recoverd g-CN still represent a thin layer appearance with TEM image attached.

In summary, a dual $\mathrm{Ni}$ /photocatalytic $\mathrm{C}\left(\mathrm{sp}^{2}\right)-\mathrm{SO}_{2} \mathrm{Ar}$ coupling was developed using a carbon nitride semiconductor as recyclable photocatalyst with low toxicity. The semi-heterogeneous nickel/carbon nitride catalysis is an inexpensive, sustainable alternative to homogeneous protocols. The method selectively couples a broad range of aryl bromides with sodium benzenesulfonate in good to excellent isolated yields. Dapsone synthesis was also demonstrated on a gram scale and cyclic experiments also demonstrated the great potential of g-CN in such reactions.

\section{ASSOCIATED CONTENT}

\section{Supporting Information}

Experimental details, materials characterization and copies of relevant NMR spectra for all new products, this material is available free.

\section{AUTHOR INFORMATION}

\section{Corresponding Author}

*Yang Liu - Frontier Institute of Science and Technology (FIST), Xi'an Jiaotong University, Yanxiang Road 99, Xi'an, Shaanxi, 710054, P. R. China.

Email: Yang_Liu.Chem@outlook.com

orcid.org/0000-0003-0036-6232

\section{Author}

Yang Liu - Frontier Institute of Science and Technology (FIST), Xi'an Jiaotong University, Yanxiang Road 99, Xi'an, Shaanxi, 710054, P. R. China.

Email: Yang_Liu.Chem@outlook.com

orcid.org/0000-0003-0036-6232

Joost Berkhong - Frontier Institute of Science and Technology (FIST), Xi'an Jiaotong University, Yanxiang Road 99, Xi'an, Shaanxi, 710054, P.R. China.

Email: J.Berkhong_chem@outlook.com

\section{Notes}

The author declares no competing financial interest.

\section{ACKNOWLEDGMENT}

We thank the Priority Academic Program Development of Shaanxi Higher Education Institutions and Postdoctoral research fund of Xi 'an Jiaotong University.

\section{REFERENCES}

(1) for reviews: (a) Chan, A. Y.; Perry, I. B.; Bissonnette, N.B.; MacMillan, D. W. C. Metallaphotoredox: The Merger of Photoredox and Transition Metal Catalysis. Chem. Rev. 2021, XXXX (b) Pitre, S. P.; Overman, L. E. Strategic Use of Visible-Light Photoredox Catalysis in Natural Product Synthesis. Chem. Rev. 2021, XXXX. (c) Narayanam, J. M. R.; Stephenson, C. R. J. Visible light 
photoredox catalysis: applications in organic synthesis. Chem. Soc. Rev. 2011, 40, 102-113. (d) Shaw, M.; Twilton.; MacMillan, D. W. C. Photoredox Catalysis in Organic Chemistry. J. Org. Chem. 2016, 81, 6898-6926.

(2) about the typical nickel metal involved in photoredox process: (a) Zuo, Z.; Ahneman, D. T.; Chu, L.; Terrett, J. A.; Doyle, A. G.; MacMillan, D. W. C. Merging Photoredox with Nickel Catalysis: Coupling of $\alpha$-Carboxyl $\mathrm{sp}^{3}$-Carbons with Aryl Halides. Science 2014, 345, 437-440. (b) Corcoran, E. B.; Pirnot, M. T.; Lin, S.; Dreher, S. D.; DiRocco, D. A.; Davies, I. W.; Buchwald, S. L.; MacMillan, D. W. C. Aryl amination using ligand-free Ni(II) salts and photoredox catalysis. Science 2016, 353, 279-283. (c) Johnston, C. P.; Smith, R. T.; Allmendinger, S.; MacMillan, D. W. C. Metallaphotoredox-catalysed $\mathrm{sp}^{3}-\mathrm{sp}^{3}$ cross-coupling of carboxylic acids with alkyl halides. Nature 2016, 536, 322-325. (d) Zuo, Z.; Cong, H.; Li, W.; Choi, J.; Fu, G. C.; MacMillan, D. W. C. Enantioselective Decarboxylative Arylation of $\alpha$-Amino Acids via the Merger of Photoredox and Nickel Catalysis. J. Am. Chem. Soc. 2016, 138, 1832-1835.

(3) (a) Zhang, H.; Zhao, J.; Yu, S. Enantioselective Allylic Alkylation with 4-Alkyl-1,4-dihydro-pyridines Enabled by Photoredox/Palladium Cocatalysis. J. Am. Chem. Soc. 2018, 140, 49, 16914-16919. (b) Zhang, H.; Zhao, J.; Yu, S. Enantioselective $\alpha$ Allylation of Anilines Enabled by a Combined Palladium and Photoredox Catalytic System. ACS Catal. 2020, 10, 4710-4716. (c) Shimomaki, K.; Murata, K.; Martin, R.; lwasawa, N. Visible-LightDriven Carboxylation of Aryl Halides by the Combined Use of Palladium and Photoredox Catalysts. J. Am. Chem. Soc. 2017, 139, 9467-9470.

(4) (a) Ye, Y.; Sanford, M. S. Merging Visible-Light Photocatalysis and Transition-Metal Catalysis in the Copper-Catalyzed Trifluoromethylation of Boronic Acids with $\mathrm{CF}_{3} \mathrm{I}$. J. Am. Chem. Soc. 2012, 134, 9034-9037. (b) Kautzky, J. A.; Wang, T.; Evans, R. W.; MacMillan, D. W. C. Decarboxylative Trifluoromethylation of Aliphatic Carboxylic Acids. J. Am. Chem. Soc. 2018, 140, 6522-6526. (c) Le, C.; Chen, T. Q.; Liang, T.; Zhang, P.; MacMillan, D. W. C. A Radical Approach to the Copper Oxidative Addition Problem: Trifluoromethylation of Bromoarenes. Science 2018, 360, 10101014. (d) Sarver, P. J.; Bacauanu, V.; Schultz, D. M.; DiRocco, D. A.; Lam, Y.; Sherer, E. C.; MacMillan, D. W. C. The Merger of Decatungstate and Copper Catalysis to Enable Aliphatic $\mathrm{C}\left(\mathrm{sp}^{3}\right)-\mathrm{H}$ Trifluoromethylation. Nat. Chem. 2020, 12, 459-467.

(5) (a) Jeffrey, J. L.; Terrett, J. A.; MacMillan, D. W. C. O-H hydrogen bonding promotes $\mathrm{H}$-atom transfer from $\alpha \mathrm{C}-\mathrm{H}$ bonds for C-alkylation of alcohols. Science 2015, 349, 1532-1536. (b) Cuthbertson, J. D.; MacMillan, D. W. C. The Direct Arylation of Allylic $\mathrm{Sp}^{3} \mathrm{C}-\mathrm{H}$ Bonds via Organic and Photoredox Catalysis. Nature $\mathbf{2 0 1 5}$ 519, 74-77. (c) Sahoo, B.; Hopkinson, M. N.; Glorius, F. Combining Gold and Photoredox Catalysis: Visible Light-Mediated Oxyand Aminoarylation of Alkenes. J. Am. Chem. Soc. 2013, 135, 5505-5508. (d) Cao, H.; Jiang, H.; Feng, H.; Kwan, J. M. C.; Liu, X.; Wu, J. Photo-Induced Decarboxylative Heck-Type Coupling of Unactivated Aliphatic Acids and Terminal Alkenes in the Absence of Sacrificial Hydrogen Acceptors. J. Am. Chem. Soc. 2018, 140, 16360-16367. (e) Lin, S.; Chen, Y.; Li, F.; Shi, C.; Shi, L. VisibleLight-Driven Spirocyclization of Epoxides: Via Dual Titanocene and Photoredox Catalysis. Chem. Sci. 2020, 11, 839-844. (f) Schwarz, J. L.; Schäfers, F.; Tlahuext-Aca, A.; Lückemeier, L.; Glorius, F. Diastereoselective Allylation of Aldehydes by Dual Photoredox and Chromium Catalysis. J. Am. Chem. Soc. 2018, 140, 12705-12709. (g) Rao, H.; Lim, C. H.; Bonin, J.; Miyake, G. M.; Robert, M. Visible-Light-Driven Conversion of $\mathrm{CO}_{2}$ to $\mathrm{CH}_{4}$ with an Organic Sensitizer and an Iron Porphyrin Catalyst. J. Am. Chem.
Soc. 2018, 140, 17830-17834. (h) Long, W.; Lian, P.; Li, J.; Wan, X. Mn-Catalysed Photoredox Hydroxytrifluoromethylation of Aliphatic Alkenes Using $\mathrm{CF}_{3} \mathrm{SO}_{2} \mathrm{Na}$. Org. Biomol. Chem. 2020, 18, 6483-6486.

(6) Cerfontaine, S.; Wehlin, S. A. M.; Elias, B.; Troian-Gautier, L. Photostable Polynuclear Ruthenium (II) Photosensitizers Competent for Dehalogenation Photoredox Catalysis at $590 \mathrm{~nm}$. J. Am. Chem. Soc. 2020, 142, 5549-5555.

(7) Bell, J. D.; Murphy, J. A. Recent advances in visible lightactivated radical coupling reactions triggered by (i) ruthenium, (ii) iridium and (iii) organic photoredox agents. Chem. Soc. Rev. 2021, 50, 9540-9685.

(8) Romero, N. A.; Nicewicz, D. A. Organic Photoredox Catalysis. Chem. Rev. 2016, 116, 10075-10166.

(9) (a) Ghosh, I.; Khamrai, J.; Savateev, A.; Shlapakov, N.; Antonietti, M.; König, B. Organic semiconductor photocatalyst can bifunctionalize arenes and heteroarenes. Science 365, 360-366. (b) Khamrai, J.; Ghosh, I.; Savateev, A.; Antonietti, M.; König, B. Photo-Ni-Dual-Catalytic C $\left(\mathrm{sp}^{2}\right)-\mathrm{C}\left(\mathrm{sp}^{3}\right)$ Cross-Coupling Reactions with Mesoporous Graphitic Carbon Nitride as a Heterogeneous Organic Semiconductor Photocatalyst. ACS Catal. 2020, 10, 35263532. (c) Pieber, B.; Malik, J. A.; Cavedon, C.; Gisbertz, S.; Savateev, A.; Cruz, D.; Heil, T.; Zhang, G. G.; Seeberger, P. H. Semiheterogeneous Dual Nickel/Photocatalysis using Carbon Nitrides: Esterification of Carboxylic Acids with Aryl Halides. Angew. Chem., Int. Ed. 2019, 58, 9575-9580. (d) Cavedon, C.; Madani, A.; Seeberger, P. H.; Pieber, B. Semiheterogeneous Dual Nickel/Photocatalytic (Thio)etherification Using Carbon Nitrides. Org. Lett. 2019, 21, 5331-5334. (e) Zhao, X.; Deng, C.; Meng, D.; Ji, H.; Chen, C.; Song, W.; Zhao, J. Nickel-Coordinated Carbon Nitride as a Metallaphotoredox Platform for the Cross-Coupling of Aryl Halides with Alcohols. ACS Catal. 2020, 10, 15178-15185.

(10) (a) Lang, X.; Zhao, J.; Chen, X. Visible-Light-Induced Photoredox Catalysis of Dye-Sensitized Titanium Dioxide: Selective Aerobic Oxidation of Organic Sulfides. Angew. Chem., Int. Ed. 2016, 55, 4697-4700. (b) McTiernan, C. D.; Pitre, S. P.; Ismaili, H.; Scaiano, J. C. Heterogeneous Light-Mediated Reductive Dehalogenations and Cyclizations Utilizing Platinum Nanoparticles on Titania (PtNP@ $\mathrm{TiO}_{2}$ ). Adv. Synth. Catal. 2014, 356, 2819-2824,

(11) (a) Liu, Y. -Y.; Liang, D.; Lu, L. -Q.; Xiao, W. -J. Practical heterogeneous photoredox/nickel dual catalysis for $\mathrm{C}-\mathrm{N}$ and $\mathrm{C}-\mathrm{O}$ coupling reactions. Chem. Commun. 2019, 55, 4853-4856. (b) Zhao, L. -M.; Meng, Q. -Y.; Fan, X. -B.; Ye, C.; Li, X. -B.; Chen, B.; Ramamurthy, V.; Tung, C. -H.; Wu, L. -Z. Photocatalysis with Quantum Dots and Visible Light: Selective and Efficient Oxidation of Alcohols to Carbonyl Compounds through a Radical Relay Process in Water. Angew. Chem., Int. Ed. 2017, 56, 3020-3024.

(12) Selected reports to see: (a) Savateev, A.; Ghosh, I.; König, B.; Antonietti, M. Photoredox Catalytic Organic Transformations using Heterogeneous Carbon Nitrides. Angew. Chem., Int. Ed. 2018, 57, 15936-15947, (b) Wang, X.; Maeda, K.; Thomas, A.; Takanabe, K.; Xin, G.; Carlsson, J. M.; Domen, K.; Antonietti, M. A metalfree polymeric photocatalyst for hydrogen production from water under visible light. Nat. Mater. 2009, 8, 76-80. (c) Wang, Y.; Wang, X.; Antonietti, M. Polymeric Graphitic Carbon Nitride as a Heterogeneous Organocatalyst: From Photochemistry to Multipurpose Catalysis to Sustainable Chemistry. Angew. Chem., Int. Ed. 2012, 51, 68-89. (d) Savateev, A.; Antonietti, M. Heterogeneous Organocatalysis for Photoredox Chemistry. ACS Catal. 2018, 8, 97909808 .

(13) Selected reports to see: (a) Khan, I.; Das, V.; Teillout, A.; Mbomekalle, I.; Oliveira, D.; Sahoo, S.; Hussain, F. Tetrameric Lanthanide-Substituted Silicotungstate $\left\{\mathrm{Ln}_{8} \mathrm{Si}_{4} \mathrm{~W}_{40}\right\}$ Nanoclusters: 
Synthesis, Structural Characterization, Electrochemistry, and Catalytic Application for Oxidation of Thioethers. Eur. J. Inorg. Chem. 2021, 11, 1071-1081. (b) Cheng, Z.; Sun, P.; Tang, A.; Jin, W.; Liu, C. Switchable Synthesis of Aryl Sulfones and Sulfoxides through Solvent-Promoted Oxidation of Sulfides with $\mathrm{O}_{2} /$ Air. Org. Lett. 2019, 21, 8925-8929. (c) Park, J.; Lee, S. Sulfoxide and Sulfone Synthesis via Electrochemical Oxidation of Sulfides. J. Org. Chem. 2021, 86, 19, 13790-13799. (d) Cacchi, S.; Fabrizi, G.; Goggiamani, A.; Parisi, L. M.; Bernini, R. Unsymmetrical Diaryl Sulfones and Aryl Vinyl Sulfones through Palladium-Catalyzed Coupling of Aryl and Vinyl Halides or Triflates with Sulfinic Acid Salts. J. Org. Chem. 2004, 69, 5608-5614. (e) Baskin, J. M.; Wang, Z. An Efficient Copper Catalyst for the Formation of Sulfones from Sulfinic Acid Salts and Aryl Iodides. Org. Lett. 2002, 4, 4423-4425. (f) Emmett, E. J.; Hayter, B. R.; Wills, M. C. Palladium-Catalyzed ThreeComponent Diaryl Sulfone Synthesis Exploiting the Sulfur Dioxide Surrogate DABSO. Angew. Chem., Int. Ed, 2013, 52, 1267912683. (g) Deeming, A. S.; Russell, C. J.; Hennessy, A. J.; Willis, M. C. DABSO-Based, Three-Component, One-Pot Sulfone Synthesis. Org. Lett. 2014, 16, 150-153. (h) Bahrami, K.; Khodei, M. M.; Shahbazi, F. Highly selective catalytic Friedel-Crafts sulfonylation of aromatic compounds using a $\mathrm{FeCl}_{3}$-based ionic liquid. Tetrahedron. Lett. 2008, 49, 3931-3934. (i) Borujeni, K. P.; Tamami, B. Polystyrene and silica gel supported $\mathrm{AlCl}_{3}$ as highly chemoselective heterogeneous Lewis acid catalysts for Friedel-Crafts sulfonylation of aromatic compounds. Cata. Com. 2007, 8, 1191-1196.

(14) (a) Cabrera, M.; Lu, Zhi.; Kelly, C.; Lang, S.; Dykstra, R.; Gutierrez, O.; Molander, G. Engaging sulfinate salts via Ni/photoredox dual catalysis enables facile $\mathrm{Csp}^{2}-\mathrm{SO}_{2} \mathrm{R}$ coupling. Chem. Sci, 2018, 9, 3186-3191. (b) Gualandi, A.; Mazzarella, D.; Ortega, A.; Mengozzi, L.; Calcinelli, F.; Matteucci, E.; Monti, F.; Armaroli, N. Photocatalytic Radical Alkylation of Electrophilic Olefins by Benzylic and Alkylic Zinc-Sulfinates. ACS Catal. 2017, 7, 5357-5362.

(15) (a) Meyer, A. U.; Lau, V. W. -H.; König, B.; Lotsch, B. V. Photocatalytic Oxidation of Sulfinates to Vinyl Sulfones with Cyanamide-Functionalised Carbon Nitride. Eur. J. Org. Chem. 2017, 15, 2179-2185. (b) Baar, M.; Blechert, S.; Graphitic Carbon Nitride Polymer as a Recyclable Photoredox Catalyst for Fluoroalkylation of Arenes. Chem. Eur. J. 2014, 20, 1-6. 